\title{
EDITORIAL
}

\section{NON-COMMUNICABLE DISEASES: BANGLADESH PERSPECTIVE}

Non-communicable diseases (NCDs) are significantly responsible for disease burden, morbidity and mortality. At least $25 \%$ of the deaths in primary and secondary government health facilities are caused by these diseases. Presently, Bangladesh does not have a community-based public health programme for NCDs. Only hospital-based information is available. ${ }^{1}$ We are being told that NCDs in the developing world represent a 'race against time'. ${ }^{2}$ Major constituents of NCD include coronary heart disease, ischaemic stroke, haemorrhagic stroke, cancers, chronic obstructive airways disease, asthma.

NCDs account for the majority of the global burden of disease and, in low and middle-income countries (LMICs), are projected to increase markedly. Table 1 shows the estimated 10 leading causes of death in 2000 Data for population surveillance of NCDs are limited in many countries. The World Health Organization has set up a range of projects aimed at improving the amount and quality of relevant data. The Surveillance of Risk Factors (SuRFs) project, launched in 2003, presents chronic disease risk factor profiles from $170 \mathrm{WHO}$ member states. These data include tobacco and alcohol use, patterns of physical inactivity, low fruit/vegetable intake, obesity, blood pressure, cholesterol, and diabetes.

The Non-communicable diseases have a considerable toll on individuals, societies and health systems. Located in South Asia, Bangladesh has a population of about 150 million and a per-capita health expenditure of US $\$ 64$ will not be sufficient enough to combat with this condition. ${ }^{3}$

The world Health Report 2002 had illustrated that NCDs accounts for almost $60 \%$ of deaths and $46 \%$ of the global burden of disease. If present trends continue, by 2020 , these diseases are expected to account for $73 \%$ of deaths and $60 \%$ of disease burden. ${ }^{4}$

The major limitations which are being faced for initiation of surveillance on NCDs include lack of advocacy, lack of logistic and other facilities as well as difficulties in the generating resources for newer initiatives. $^{2}$

Table -I

Estimated 10 leading causes of death in 2000

\begin{tabular}{|c|c|c|c|c|c|c|}
\hline 2000 & World & & Developed countries ${ }^{a}$ & & Developing countries & \\
\hline Rank & Causes & $\%$ Total & Causes & $\%$ Total & Causes & $\%$ Total \\
\hline 1. & Ischaemic heart disease & 12.4 & Ischaemic heart disease & 22.6 & Ischaemic heart disease & 9.1 \\
\hline 2. & Cerebrovascular disease & 9.2 & Cerebrovascular disease & 13.7 & Cerebrovascular disease & 8.0 \\
\hline 3. & $\begin{array}{l}\text { Lower respiratory } \\
\text { Infections }\end{array}$ & 6.9 & $\begin{array}{l}\text { Trachea, bronchus, and } \\
\text { lung cancers }\end{array}$ & 4.5 & Lower respiratory infections & s 7.7 \\
\hline 4. & HIV/AIDS & 5.3 & Lower respiratory infections & s 3.7 & HIV/AIDS & 6.9 \\
\hline 5. & $\begin{array}{l}\text { Chronic opbstructive } \\
\text { pulmonary diseases }\end{array}$ & 4.5 & $\begin{array}{l}\text { Chronic obstructive } \\
\text { pulmonary diseases }\end{array}$ & 3.1 & Perinatal conditions & 5.6 \\
\hline 6. & Perinatal conditions & 4.4 & Colon and rectal cancers & 2.6 & $\begin{array}{l}\text { Chronic obstructive } \\
\text { pulmonary disease }\end{array}$ & 5.0 \\
\hline 7. & Diarrhoeal diseases & 3.8 & Stomach cancer & 1.9 & Diarrhoeal disease & 4.9 \\
\hline 8. & Tuberculosis & 3.0 & Self-inflicted injury & 1.9 & Tuberculosis & 3.7 \\
\hline 9. & Road traffic accidents & 2.3 & Diabetes & 1.7 & Malaria & 2.6 \\
\hline 10. & $\begin{array}{l}\text { Trachea, bronchus and } \\
\text { Lung cancer }\end{array}$ & 2.2 & Breast cancer & 1.6 & Road traffic accidents & 2.5 \\
\hline
\end{tabular}

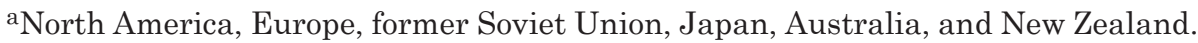

Sources: World Health Organization, Geneva (2002) Beaglehole R and Yach D, 2003. 
Globalization, unplanned urbanization and environmental and life style factors on a background of over population have been contributing significantly to increase burden of NCDs. It is estimated that by 2010, NCDs will be responsible for 59\% of deaths, compared to $40 \%$ in 1990 . Although the country is lacking a good surveillance system, the magnitude of NCDs is considered to be fairly high in Bangladesh. In 2000, top ten causes of death in Bangladesh included asthma/COPD, stroke, heart diseases, hypertension and diabetes. ${ }^{5}$

NCD surveillance is a new endeavor in Bangladesh. Therefore, its plan of implementation needs to be simple and easily administrable. Systematic collection, analysis and interpretation of health data and the timely dissemination of this data to policymakers and others are required to implement an effective surveillance system. WHO is pursuing surveillance as part of a global strategy for preventing and controlling NCDs. The WHO STEP wise approach to surveillance of NCD risk factors uses a standard survey instrument and a methodology that can be adapted to different country resource settings and help to build country capacity. ${ }^{6}$

We believe that some NCDs in most LMICs are a priority now and it would be a serious mistake to ignore their prevention and control in the coming decade. What sort of response should be made? Primary prevention can be the key. It is the key to control of the global epidemic of NCDs especially in LMIC like Bangladesh. ${ }^{7}$ Prevention of NCDs through promotion of healthy life style is necessary during all phase of life. In LMICs it will be necessary to ensure that interventions focused on improving eating habits and activity patterns are not ignored in preference to drug treatments. However, It would be useful for international agencies, governments, and funding agencies to debate and produce a common agenda for action on NCDs-in the same way as has been done for communicable diseases-focused on their causes, prevention, and control within the context of the broader health care system, and including systematic review of available evidence, needs for new research, education, training, and capacity development.

\section{Prof. A K M Rafique Uddin}

Professor \& Head, Department of Medicine

Enam Medical College, Savar,Dhaka.

\section{References:}

1. World Health Organization Bangladesh. NCD \& Mental Health. Surveillance, Prevention and Management of Non-communicable Diseases. Available at: www.whoban.org/nc_dis_surv.html. Accessed August, 2008.

2. Leeder S, Raymond S, Greenberg H, Liu H, Esson K. A Race Against Time: The Challenge of Cardiovascular Disease in Developing Countries. New York: Center for Global Health and Economic Development, Earth Institute, Mailman School of Public Health, Columbia University, 2004.

3. World Health Organization. Core Health Indicators 2007 Database. Available at: www.who.int/whosis/ database. Accessed July, 2007.

4. World Health Organization. The World Heal Report 2002. Available at: www.who.int/whr/2002/annex/en.

5. Strategic plan for Surveillance and prevention of noncommunicable diseases in Bangiadesh, 2007-2010. Director General of Health Services, Ministry of Health and Family Welfare, 2007.

6. World Health Organization. Noncommunicable Disease Surveillance. Available at: www.who.int/ ncd_surveillance/en/. Accessed 2008.

7. Joshi SR. 'Polypill-aspostatinoprilololazide folate'coprescription for at the risk Asian Indian in chronic non communicable diseases. J Assoc Phys India 2005; 53: $175-8$. 